\title{
Transient erythroblastopenia of childhood with CD10, TdT, and cytoplasmic $\mu$ lymphocyte positivity in bone marrow
}

\author{
A B M Foot, M N Potter, J E Ropner, T B Wallington, A Oakhill
}

\begin{abstract}
Over three years, three children presented with anaemia, reticulocytopenia, and marrow erythroblastopenia. A pronounced lymphocytosis was also evident in two of the marrow aspirates, with increased numbers of cells bearing the immunophenotype TdT,+ CD10 + HLA $\mathbf{D R}+$, and cytoplasmic $\mu+$, and reported to be compatible with acute lymphoblastic leukaemia (ALL). The clinical course of the illness was fully compatible with transient erythroblastopenia of childhood (TEC), and all three children remained well one to four years after initial presentation. It is concluded that increased numbers of lymphoid cells with a common or pre-B ALL phenotype may be found in bone marrow aspirates of children with TEC, and should not be misdiagnosed as acute leukaemia.
\end{abstract}

Transient erythroblastopenia of childhood (TEC) is a self-limiting disorder of unknown aetiology, characterised by an anaemia lasting a few weeks. Since it was first described in $1970^{12}$ this condition has been recognised increasingly in children in the United States, ${ }^{3}$ although a review of the literature suggests that it is less common in Europe, with few reported cases in the United Kingdom. Although typically described as a pure red cell hypoplasia, the finding of clinically important neutropenia is not uncommon, ${ }^{3}$ and bone marrow aspiration is advisable to rule out the possibility of malignancy.

\section{Methods}

Over three years (1985-1988), three children, previously in good health, presented with anaemia; preliminary investigation showed that one was also neutropenic. Bone marrow aspiration was performed in each case. Cell surface marker studies were performed on sterile samples of bone marrow. In brief, after separation on a Ficoll-Hypaque gradient the washed mononuclear cells were labelled with mouse monoclonal antibodies or conventional anti-sera to $\mathrm{CD} 3, \mathrm{CD} 7, \mathrm{CD} 21, \mathrm{CD} 10$, HLA $\mathrm{DR}$ and $\kappa$ or $\lambda$. After a further wash cells were

Table 1 Patient details and presenting data

\begin{tabular}{lllllllll}
\hline $\begin{array}{l}\text { Case } \\
\text { No }\end{array}$ & $\begin{array}{l}\text { Age } \\
(\text { years })\end{array}$ & Sex & Presentation & $\begin{array}{l}\text { Haemoglobin } \\
(\mathrm{g} / \text { dl) }\end{array}$ & $\begin{array}{l}\text { White cell count/ } \\
\text { neutrophils } \\
\left(\times 10^{9} / l\right)\end{array}$ & $\begin{array}{l}\text { Platelets } \\
\left(\times 10^{9} / l\right)\end{array}$ & $\begin{array}{l}\text { Mean } \\
\text { corpuscular } \\
\text { volume }(f l)\end{array}$ & $\begin{array}{l}\text { Reticulocytes } \\
(\%)\end{array}$ \\
\hline 1 & $2 \cdot 2$ & F & Hemiparesis Pallor & $2 \cdot 7$ & $10 \cdot 6 / 5 \cdot 2$ & 445 & 77 & 0 \\
2 & $4 \cdot 1$ & M & Hemiparesis Pallor & $6 \cdot 0$ & $5 \cdot 4 / 1 \cdot 6$ & 478 & 77 & $0 \cdot 2$ \\
3 & $2 \cdot 9$ & F & Pallor & 4.5 & $6 \cdot 5 / 0 \cdot 7$ & 575 & 83 & 1 \\
\hline
\end{tabular}

treated with fluorescein conjugated with antimouse or appropriate species immunoglobulin, washed, and mounted on microscope slides. The percentage of cells reacting with each reagent was assessed by fluorescence microscopy, counting at least 100 cells for each specificity. For detection of TdT and cytoplasmic $\mu$, cytocentrifuge preparations of separated mononuclear cells were fixed before reacting with appropriate polyclonal antibodies, again using an indirect immunofluorescence method.

\section{Case reports}

Details of the relevant laboratory data are described in tables 1 and 2.

\section{CASE 1}

A 2 year old girl presented to the paediatric casualty department with a history of transient right hemiparesis on two occasions during the preceding fortnight, each associated with exertion. She had become increasingly pale and lethargic over this time, although her general health remained good. The family history was unremarkable, and in particular, there was no history of migraine, neurological, or immunological disorders. She had had no recent infections, and there had been no known exposure to either drugs or toxins. On examination she had noticeable pallor and exhibited cardiovascular compensation of severe anaemia with tachycardia and a haemic flow murmur. Although there was no lymphadenopathy, her liver edge was palpable below the costal margin. Neurological examination showed that there was no residual deficit.

Table 2 Details of bone marrow lymphocyte counts and subsets

\begin{tabular}{llll}
\hline & Case 1 & Case 2 & Case 3 \\
\hline $\begin{array}{l}\text { Lymphocyte count as } \\
\text { percentage of total }\end{array}$ & 17 & 51 & 48 \\
nucleated cells & 53 & 65 & 10 \\
CD10 & 64 & 80 & 71 \\
DR & 70 & 50 & 20 \\
TdT & 10 & 40 & 10 \\
Cytoplasmic $\mu$ & 61 & Not done & 75 \\
T cell: CD3 & Not done & 20 & 69 \\
CD7 & 17 & Not done & Not done \\
B cell: SIg & Not done & 60 & 28 \\
\hline CD21 & & & \\
\hline
\end{tabular}

Gloucestershire Royal

Hospital

J E Ropner

Department of

Immunology,

Southmead Hospital,

Bristol

T B Wallington

Correspondence to:

Dr A B M Foot

Accepted for publication

2 July 1990 
Initial investigations confirmed severe anaemia with normal indices and absent reticulocytes, together with thrombocytosis (table 1). Further tests excluded haemolysis and congenital forms of red cell aplasia; Ham's acid and sucrose lysis tests were negative. Haemoglobin $\mathrm{F}$ ( $\mathrm{Hb} \mathrm{F}$ ) estimation was mildly increased at $2.5 \%$. A virological screen, which included Epstein-Barr virus, cytomegalovirus, and parvovirus, was negative.

Bone marrow examination showed erythroblastopenia but normal myeloid and megakaryocytic activity and a correspondingly high myeloid:erythroid ratio of 18:1. The lymphocyte count was $17 \%$, and all seemed to be normal with no immature cells. Monoclonal surface markers, however, were reported as being compatible with a diagnosis of common ALL (table 2).

A blood transfusion was given, raising her haemoglobin to $7.5 \mathrm{~g} / \mathrm{dl}$, but no further active treatment was given. She subsequently exhibited a moderate reticulocytosis, her haemoglobin attaining normal concentrations six weeks after presentation, and she continued to be in good health four years later.

CASE 2

A 4 year old boy visiting relatives away from his home town presented to the local casualty with an episode of transient right hemiparesis. Three weeks before this he had been admitted to hospital for observation following a head injury sustained after a fall from a bench. The previous day he had been to see his own general practitioner, who had diagnosed anaemia. He was therefore referred to his local hospital for further investigation. His medical history showed that he had had bilateral talipes and clicky hip, treated conservatively with splints and casts, and a right inguinal hernia repair, but again family history was unremarkable. Clinical examination confirmed pallor and a haemic flow murmur, but was otherwise normal, and there was no residual neurological deficit.

On admission he was noted to be moderately anaemic, with mild thrombocytosis and a normal total white cell count. The blood film, however, showed the presence of atypical mononuclear cells and reactive lymphocytes. Further investigation for both haemolysis and congenital red cell aplasia yielded negative results. Hb F estimation was $2 \cdot 1 \%$. A viral antibody screen was negative, including for parvovirus, and there was no evidence for toxins or drugs to be the cause of his red cell hypoplasia.

Bone marrow examination confirmed depressed erythropoiesis but normal granulopoiesis and increased numbers of megakaryocytes. The myeloid:erythroid ratio was calculated at 6:1. A lymphocytosis of $51 \%$ of the total nucleated cell count was also noted, which, morphologically, was small and mature with no excess of blasts. Marker studies, however, showed that most of these cells were primitive, primarily at the pre-B stage, and were reported as being highly suggestive of
ALL. In view of the abnormal cells visualised on the blood film, monoclonal markers of peripheral blood cells were also performed which showed a pre-B population of $5 \%$.

The child was treated symptomatically only, receiving a red cell transfusion. His anaemia resolved over the ensuing weeks, and he remained well, 15 months after this episode.

\section{CASE 3}

A girl, almost 3 years of age, presented to her local hospital with increasing lethargy and pallor; she was otherwise asymptomatic. Examination showed that she was clinically anaemic and had a liver edge palpable below the costal margin, although there was no obvious lymphadenopathy. Severe anaemia was confirmed on investigation, but she was also noted to have a neutropenia and thrombocytosis. As with the previous cases, there was no evidence of haemolysis or congenital red cell aplasia, and a viral screen was negative.

A bone marrow aspiration showed depression of erythropoiesis but active myelopoiesis and plentiful megakaryocytes. The myeloid: erythroid ratio was $8: 1$. As with case 2 , however, a lymphocytosis of $48 \%$ of the mononuclear cells was noted, most of which were small and mature, but $8 \%$ were large with prominent nucleoli. Marker studies again showed the presence of a primitive population, although at a lower percentage than the previous cases.

She received a red cell transfusion, after which she maintained her haemoglobin, with a reticulocyte response. She has remained well during the 15 months since this episode.

\section{Discussion}

Transient anaemia, reticulocytopenia, and marrow erythroblastopenia in a child without underlying haematological disease constitute the classic triad of TEC. Typically, the patient falls into the pre-school age group and is otherwise well. The erythrocyte characteristics readily distinguish TEC from both congenital hypoplastic anaemias and iron deficiency anaemia, the red cells being normochromic and normocytic with entirely mature features. In the recovery phase, however, erythrocytes with fetal characteristics may be detected, in common with other forms of marrow stress, ${ }^{4}$ and a transient rise in $\mathrm{Hb} \mathrm{F}$ production is often observed, as noted in two of our cases.

Although typically described as a pure red cell aplasia, there are often accompanying disturbances of both platelet and white cell production. Thrombocytosis is frequently observed, ${ }^{5}$ and neutropenia is not uncommon ${ }^{3}$; both of these features were noted in our cases. An associated neutropenia may lead to doubt over the benign diagnosis, and examination of the bone marrow is recommended to exclude malignancy.

In TEC the finding of erythroblastopenia in the marrow aspirate is universal. Previous series, however, have reported the additional finding of a lymphocytosis containing high percentages of young lymphoid cells, raising 
the suspicion of leukaemia. ${ }^{67}$ Gerrits et al studied one such case in greater detail, using immunofluorescence markers, and found a subpopulation of 7\% showing cALLa positivity. We, too, found an accompanying lymphocytosis in two of our cases, and although morphology showed most to be small and mature, marker studies identified a large immature population in all three. The normal marrow in children may contain a population of up to $5 \%$ of mononuclear cells at an early stage of B lymphocyte differentiation, expressing TdT, HLA DR, and CD10, but the finding of proportions much in excess of this is characteristically associated with common ALL. In some other non-malignant blood disorders increased numbers of cells bearing the same immature phenotype have been described. This is particularly so in stressed or regenerating marrows following cytotoxic treatment, bone marrow transplantation, and aplastic anaemia, and the distinction from leukaemic blasts has proved difficult using this characteristic alone. ${ }^{8}$ It has been suggested that they represent a population of regenerating lymphoid cells, most probably of early B lineage. The finding of CD10 positivity, together with $\mathrm{TdT}$ and cytoplasmic $\mu$ positivity in all of our cases, gives the picture of an immature population of cells, predominantly at the pre-B stage. This could mistakenly be interpreted as ALL, out of context with the clinical and morphological findings. Transient pancytopenia with documented recovery before the development of ALL (the syndrome of "pre-leukaemic aplasia") can occur in common ALL.9 All patients described in that series, however, had proceeded to overt leukaemia within a year of primary presentation of their transient hypoplasia.

The finding of bone marrow lymphocytosis in TEC, as seen in two of our cases, remains unexplained. Clinically important lymphocytosis has also been noted in cases of congenital hypoplastic anaemia, and in one case has even led to treatment with cytotoxic agents on the erroneous assumption that this represented acute leukaemia. ${ }^{10}$ Miale et al argued that these young lymphoid cells could be erythroid precursors, ${ }^{10}$ and Inoui et al have documented B lymphocyte antigens on erythroid colony and burst forming cells. ${ }^{11}$ In our cases, however, it is clear that the lymphocytosis is a consequence of an outpouring of immature lymphocytes, and is consistent with other examples of a stressed marrow.

Although the aetiology remains obscure, reports of clustering implicate an infectious agent. ${ }^{3512}$ It is of particular interest to note that in case 3 most of the lymphocyte population consists of mature reactive $T$ cells, as shown by CD3 and HLA DR positivity. Unlike the documented link between human parvovirus B19 infection and aplastic crises in patients with chronic haemolytic anaemia, however, ${ }^{13}$ no particular agent has as yet been identified. This is confirmed in our series, with negative virological screening, including IgG and IgM specific parvovirus antibodies. The presence of reactive lymphocytosis is also suggestive of an immunological response. The mechanism of the anaemia in TEC has previously been explored, and in many cases seems to have an autoimmune element. ${ }^{14-17}$ The mode of suppression of erythropoeisis, however, does not seem to be uniform, with IgG, IgM, and cell mediated inhibition all documented. Thus both aetiology and the mechanism of TEC seem to be heterogenous, but yet result in a uniform syndrome.

Finally, it is interesting to note that two of these children presented xrith transie: + hemiparesis. The association of transient neurological disorder at presentation of TEC has been reported. ${ }^{18-20}$ In a case report Young et al proposed that the transient hemipareses in an anaemic child (haemoglobin concentration $4 \mathrm{~g} / \mathrm{dl}$ ) might have been caused by anaemic hypoxia, and they support this with hypothetical calculations. ${ }^{18}$ The range of anaemia at onset of neurological disturbance $(4 \cdot 2-9 \cdot 1$ $\mathrm{g} / \mathrm{dl}$ ) and the varied symptomatology described in the small series by Michelson and Marshall, however, would suggest a more complex, as yet unknown aetiology. ${ }^{20}$

In conclusion, a marrow lymphocytosis with CD10, TdT, and cytoplasmic $\mu$ positivity can occur in TEC. Although clinical features and bone marrow morphology should suggest the diagnosis of the benign condition of TEC, the occurrence of immature lymphocytes should be recognised to prevent a false diagnosis of leukaemia.

\section{Dr A B M Foot is supported by the Alex Wolton Trust.}

1 Lovric VA. Anaemia and temporary erythroblastopenia in children. Aust Ann Med 1970;1:34-9.

2 Wranne L. Transient erythroblastopenia in infancy and childhood. Scand J Haematol 1970;7:76-81.

3 Glader BE. Diagnosis and management of red cell aplasia in children. Hematol Oncol Clin North Am 1987;1:431-47.

4 Link MP, Alter BP. Fetal-like erythropoiesis during recovery from transient erythroblastopenia of childhood. Pediatr Res 1981;15:1036-9.

5 Labotka RJ, Maurer HS, Honig GR. Transient erythroblastopenia of childhood. Review of 17 cases, including a pair of identical twins. Am J Dis Child 1981;135:937-40.

6 Gerrits GPJM, van Oostrom CG, de Vaan GAM, Bakkeren JAJM. Transient erythroblastopenia of childhood. A
review of 22 cases. Eur J Pediatr 1984;142:266-70.

7 Hirt A, Luthy A, Muller B, Gugler E, Wagner HP. Die transitorische Erythroblastopenie des Kindesalters. Schweiz Med Wschr 1988;118:703-7.

8 Greaves MF, Hariri G, Newman RA, Sutherland DR, Ritter MA, Ritz J. Selective expression of the common acute lymphoblastic leukemia (gp 100) antigen on immature lymphoid cells and their malignant counterparts. Blood 1983;61:628-39.

9 Breatnach F, Chessells JM, Greaves MF. The aplastic presentation of childhood leukaemia: a feature of common-ALL. Br J Haematol 1981;49:387-93.

10 Miale TD, Bloom GE. The significance of lymphocytosis in congenital hypoplastic anemia. J Pediatr 1975;87:550-3.

11 Inoue S, Kaplan J, Ottenbreit MJ. Human erythroid precursors express human B lymphocyte antigens (HBLA). Pediatr Res 1979;13:433.

12 Bhambhani $\mathrm{K}$, Inoue S, Sarnaik SA. Seasonal clustering of transient erythroblastopenia of childhood. Am J Dis Child 1988;142:175-7.

13 Anderson LJ. Role of parvovirous B19 infection in human disease. Pediatr Infect Dis J 1987;6:711-8.

4 Koenig HM, Lightsy AL, Nelson DP, Diamond LK. Immune suppression of erythropoeisis in transient erythroblastopenia of childhood. Blood 1979;54:742-6.

15 Dessypris EN, Krantz SB, Roloff JS, Lukens JN. Mode of action of the IgG inhibitor of erythropoeisis in transient

16 Freedman $M H$, Saunders EF. Transient erythroblastopenia of childhood; varied pathogenesis. Am J Hematol 1983;14:247-54.

17 Hanada T, Abe T, Takita H. T-cell mediated inhibition of erythropoeisis in transient erythroblastopenia of childhood. Br J Haematol 1985;59:391-2.

18 Young RSK, Rannels DE, Hilmo A, Gerson JM, Goodrich D. Severe anemia in childhood presenting as transient ischemic attacks. Stroke 1983;14:622-3.

19 Green NS, Garvin JH, Chutorian A. Transient erythroblastopenia of childhood presenting with papilledema. Clin Pediatr 1986;25:278-9.

20 Michelson AD, Marshall PC. Transient neurological disorder associated with transient erythroblastopenia of childhood. Am J Pediatr Hematol/Oncol 1989;9:161-3. 